\title{
A new aggressive xenograft model of human colon cancer using cancer-associated fibroblasts
}

\author{
Ester Fernando-Macías ${ }^{1,2}$, María Teresa Fernández-García ${ }^{3}$, Eva García-Pérez ${ }^{4}$, Belén Porrero-Guerrero ${ }^{1}$, Camilo \\ López-Arévalo ${ }^{1}$, Raquel Rodríguez-Uría ${ }^{1}$, Sandra Sanz-Navarro ${ }^{1}$, José Fernando Vázquez-Villa ${ }^{2}$, María Carmen \\ Muñíz-Salgueiro ${ }^{3}$, Laura Suárez-Fernández ${ }^{2}$, José A Galván ${ }^{5}$, Clara Barneo-Caragol ${ }^{2,6}$, Marcos García-Ocaña ${ }^{7}$, \\ Juan R de los Toyos ${ }^{2,8}$, Luis Barneo-Serra ${ }^{\text {Corresp. 1, 2,9 }}$ \\ ${ }^{1}$ Service of Surgery, Hospital Universitario Central de Asturias, Oviedo, Spain \\ 2 Instituto de Investigación Sanitaria del Principado de Asturias, Oviedo, Spain \\ 3 Laboratory of Department of Molecular Histopathology in Animal Cancer Models, Oncology University Institute of the Principality of Asturias, University of \\ Oviedo, Oviedo, Spain \\ 4 Ophtalmologic Research Foundation, Oviedo, Spain \\ 5 Translational Research Unit. Institute of Pathology, University of Bern, Bern, Switzerland \\ 6 Laboratory of Medicine, Department of Clinical Biochemistry, Hospital Universitario Central de Asturias, Oviedo, Spain \\ 7 Biotechnological and Biomedical Assays Unit, Technical-Scientific Services, University of Oviedo, Oviedo, Spain \\ 8 Immunology Department, School of Medicine and Health Sciences, University of Oviedo, Oviedo, Spain \\ ${ }^{9}$ Surgery Department, School of Medicine and Health Sciences, University of Oviedo, Oviedo, Spain \\ Corresponding Author: Luis Barneo-Serra \\ Email address: Ibarneo@uniovi.es
}

Background: Colorectal cancer is the second leading cause of cancer death. Almost half of the patients present recurrence within 5 years after the treatment of the primary tumor, the majority, with metastasis. On the other hand, in the search for new animal models that simulate metastatic cancer, it has been suggested that fibroblasts immersed in the peritumoral stroma (cancer-associated fibroblasts (CAFs)), play a relevant role in the development of cancer. The objective of this study was to identify an adequate animal model to study metastatic colon cancer and the application of new treatments.

Methods: Human CAFs and normal fibroblasts (NF) for transplant and culture were obtained from surgical fresh samples of patients with adenocarcinoma of sigmoid colon. Stromal cell purity was evaluated by morphology and immunostaining with vimentin (VIM) as a fibroblast marker and antiproColXI 1 as a specific human CAF marker. Phenotypic characterizacion of cultured stromal cells costaining with mesenchymal and epithelial cell markers. For identification in mice, human CAFs were labeled with the PKH26 red fluorescence dye. Cell line HT-29 were used as tumor cells. Transplant in the head of the pancreas of 34 SCID mice was performed in four different groups, as follows: I. 150,000 CAFS ( $n=12$ ), Ila. 1.5 million HT29 cells $(n=7)$, Ilb. $150,000 N F+1.5$ million HT29 cells $(n=5)$, III. 150,000 CAFS +1.5 million HT29 cells $(n=10)$. After euthanasia performed 1 month later, histological analysis was made using hematoxylin-eosin and anti- proColXI $\alpha 1$. A histopathological score system based on three features (tumor volume size, desmoplasia and number of metastasized organs) was established to compare the tumor severity.

Results: The CAFs and NF cultured were proColXI $\alpha 1+/ \mathrm{NIM}+$, proColXI $1 /$ alphaSMA+ and proColXI $1+/ C K 19+$ in different proportions without differences among them, but the CAFs growth curve was significantly larger than that of the NF $(p<0.05)$. No tumor developed in those animals that only received CAFs. When comparing group II $(\mathrm{a}+\mathrm{b})$ vs group III, both groups showed $100 \%$ hepatic

PeerJ reviewing PDF | (2019:11:43013:1:1:REVIEW 12 Mar 2020) 
metastases. Median hepatic nodules, tumor burden, lung metastases and severity score were bigger in group III vs group II $(a+b)$, although without being significant, except in the case of the median tumor volume, that was significantly higher in group III (154.8 (76.9-563.2) $\mathrm{mm}^{3}$ ) vs group II (46.7 (3.7-239.6) $\left.\mathrm{mm}^{3}\right), p=0.04$. A correlation was observed between the size of the tumor developed in the pancreas and the metastatic tumor burden in the liver and with the severity score.

Conclusion: Our experiments demonstrate that cultured CAFs have a higher growth than NF and that when human CAFs are associated to human tumor cells, larger tumors with liver and lung metastases are generated than if only colon cancer cells with/without NF are transplanted. This emphasizes the importance of the tumor stroma, and especially the CAFs, in the development of cancer. 
1 A NEW AGGRESSIVE XENOGRAFT MODEL OF

2 HUMAN COLON CANCER USING CANCER-

3 ASSOCIATED FIBROBLASTS

4

5

6

Ester Fernando-Macías ${ }^{1,2}$, M Teresa Fernández-García ${ }^{3}$, Eva García-Pérez ${ }^{4}$, Belén PorreroGuerrero $^{1}$, Camilo López-Arévalo ${ }^{1}$, Raquel Rodríguez-Uría ${ }^{1}$, Sandra Sanz-Navarro ${ }^{1}$, J Fernando Vázquez-Villa ${ }^{2}$, M Carmen Muñiz-Salgueiro ${ }^{3}$, Laura Suárez-Fernández², José A Galván ${ }^{5}$, Clara Barneo-Caragol ${ }^{2,6}$, Marcos García-Ocaña ${ }^{7}$, Juan R de los Toyos ${ }^{2,8}$, Luis Barneo-Serra ${ }^{1,2,9^{*}}$

${ }^{1}$ Service of Surgery, Hospital Universitario Central de Asturias, Oviedo, Spain ${ }^{2}$ Instituto de Investigación Sanitaria del Principado de Asturias, Oviedo, Spain ${ }^{3}$ Laboratory of Department of Molecular Histopathology in Animal Cancer Models, Oncology University Institute of the Principality of Asturias, University of Oviedo, Oviedo, Spain ${ }^{4}$ Ophtalmologic Research Foundation, Oviedo, Spain ${ }^{5}$ Translational Research Unit. Institute of Pathology, University of Bern, Bern, Switzerland ${ }^{6}$ Laboratory of Medicine, Department of Clinical Biochemistry, Hospital Universitario Central de Asturias, Oviedo, Spain

${ }^{7}$ Biotechnological and Biomedical Assays Unit, Technical-Scientific Services, University of Oviedo, Oviedo, Spain

${ }^{8}$ Immunology Department, School of Medicine and Health Sciences, University of Oviedo, Oviedo, Spain

${ }^{9}$ Surgery Department, School of Medicine and Health Sciences, University of Oviedo, Oviedo, Spain

\section{*Corresponding author:}

Luis Barneo Serra

Service of Surgery

Hospital Universitario Central de Asturias

Avenida de Roma, s/n, 33011

Oviedo, Asturias, Spain

E-mail: 1barneo@uniovi.es 


\section{Abstract}

Background: Colorectal cancer is the second leading cause of cancer death. Almost half of the patients present recurrence within 5 years after the treatment of the primary tumor, the majority, with metastasis. On the other hand, in the search for new animal models that simulate metastatic cancer, it has been suggested that fibroblasts immersed in the peritumoral stroma (cancer-associated fibroblasts (CAFs)), play a relevant role in the development of cancer. The objective of this study was to identify an adequate animal model to study metastatic colon cancer and the application of new treatments.

Methods: Human CAFs and normal fibroblasts (NF) for transplant and culture were obtained from surgical fresh samples of patients with adenocarcinoma of sigmoid colon. Stromal cell purity was evaluated by morphology and immunostaining with vimentin (VIM) as a fibroblast marker and anti-proColXI $\alpha 1$ as a specific human CAF marker. Phenotypic characterizacion of cultured stromal cells co-staining with mesenchymal and epithelial cell markers. For identification in mice, human CAFs were labeled with the PKH26 red fluorescence dye. Cell line HT-29 were used as tumor cells. Transplant in the head of the pancreas of 34 SCID mice was performed in four different groups, as follows: I. 150,000 CAFS ( $\mathrm{n}=12)$, IIa. 1.5 million HT29 cells $(n=7)$, IIb. 150,000 NF+1.5 million HT29 cells ( $n=5)$, III. 150,000 CAFS +1.5 million HT29 cells $(n=10)$. After euthanasia performed 1 month later, histological analysis was made using hematoxylin-eosin and anti- proColXI $\alpha 1$. A histopathological score system based on three features (tumor volume size, desmoplasia and number of metastasized organs) was established to compare the tumor severity.

Results: The CAFs and NF cultured were proColXI $\alpha 1+/ \mathrm{VIM}+$, proColXI $\alpha 1 /$ alphaSMA+ and proColXI $\alpha 1+/ \mathrm{CK} 19+$ in different proportions without differences among them, but the CAFs growth curve was significantly larger than that of the NF $(p<0.05)$. No tumor developed in those animals that only received CAFs. When comparing group II $(\mathrm{a}+\mathrm{b})$ vs group III, both groups showed $100 \%$ hepatic metastases. Median hepatic nodules, tumor burden, lung metastases and severity score were bigger in group III vs group II $(\mathrm{a}+\mathrm{b})$, although without being significant, except in the case of the median tumor volume, that was significantly higher in group III (154.8 (76.9-563.2) $\left.\mathrm{mm}^{3}\right)$ vs group II (46.7 (3.7-239.6) $\left.\mathrm{mm}^{3}\right), p=0.04$. A correlation was observed between the size of the tumor developed in the pancreas and the metastatic tumor burden in the liver and with the severity score.

Conclusion: Our experiments demonstrate that cultured CAFs have a higher growth than $\mathrm{NF}$ and that when human CAFs are associated to human tumor cells, larger tumors with liver and 
72 lung metastases are generated than if only colon cancer cells with/without NF are transplanted.

73 This emphasizes the importance of the tumor stroma, and especially the CAFs, in the development of cancer.

75

76

\section{Introduction}

Colorectal cancer is the third most frequent cancer worldwide, with 1.8 million estimated new cases in 2018. In terms of mortality, colorectal cancer is the second leading cause of cancer death, after lung cancer, with 880,000 deaths in 2018 [1,2]. Colon cancer is three times more frequent than rectal cancer, and $97 \%$ of colon tumors are adenocarcinomas [3]. Worldwide there is large geographic variability in incidence, and these differences are similar in both sexes $[1,4]$. The highest rates of colon cancer correspond to industrialized countries [5]. Although survival rates of advanced stage tumors have improved significantly; almost $50 \%$ of patients present with cancer recurrence within 5 years following treatment of the primary tumor, with the majority of these cases having liver metastases [6,7].

The objective of this study was to identify an adequate animal model to study metastatic colon cancer and the application of new treatments. The ideal animal model needs to meet criteria of technical ease, a high degree of implantation in a short time period, be reproducible, and with a natural history similar to the human disease. To meet these requirements and facilitate the development of cancer, the peritumoral stroma and the fibroblasts immersed in it - cancerassociated fibroblasts (CAFs) — play a relevant role [8,9]. CAFs constitute a heterogeneous group of peritumoral fibroblasts that have properties similar to those of mesenchymal stem cells [10-13]. It is thought that fibroblasts facilitate tumor growth and favor an immunosuppressive environment that avoids the elimination of tumor cells and promotes the sequestration of drugs and the radioprotection of tumor cells [14]. Therefore, the co-transplant of tumor cells with CAFs could be of interest in animal models of human cancer. The reasons that justify cotransplanting with CAFs are that they secrete growth factors, promote angiogenesis, transfer substrates to neighboring cells, and decrease the activity of natural killer cells (NK) to modulate the immune response. Previous evidence has shown that the conjoint implantation of cancerous cells with CAFs in SCID (severe combined immune deficiency) mice results in a very aggressive tumor with large local growth and liver metastases 3-4 weeks post-transplant [15]. This, along with the characteristics mentioned above, led us to develop a highly aggressive heterotopic human colon adenocarcinoma xenotransplantation model, whose results we present in this paper. The pancreas was selected as the implantation site as it is a site rich in growth factors that would facilitate local growth and distant growth from the implanted cells. 


\section{Materials \& Methods}

111

\section{Patient Characteristics and Surgical Samples}

113 The CAFs for transplant were obtained from an 81-year-old woman with moderately

114 differentiated adenocarcinoma of the sigmoid colon, pT3 pN0. The human fibroblasts for culture

115 were obtained from three patients: 1) an 80-year-old male with a well-differentiated mucinous

116 adenocarcinoma of the right colon, pT2 pN0; 2) a 72-year-old female with a moderately

117 differentiated adenocarcinoma of the sigmoid colon, pT3 pN0; and 3) a 56-year-old male with a

118 recurrence of moderately differentiated adenocarcinoma of the sigmoid colon, pT3pN0.

119

\section{Cell Cultures}

121 Colon fibroblasts

122

123

Samples were obtained from the tumor area (for other studies), peritumoral area (for CAFs) and normal area (for "normal fibroblasts", NF) using different surgical blades to avoid contamination few minutes after the operation. The lack of tumor cells was verified by

125 microscopy. The samples were cut into smaller fragments. The establishment of cell cultures has been published previously [16]. Briefly, the fragments were enzymatically digested with collagenase Type I, the pellet was suspended in a fibroblast culture medium with fetal bovine serum (FBS) as below and antibiotics. The tissue fragments that had not been digested with collagenase underwent a second digestion with trypsin and EDTA. Cells obtained were seeded in six-well plates using fibroblast culture medium and maintained at $37^{\circ} \mathrm{C}$ in a $5 \% \mathrm{CO}_{2}$ incubator. All stromal cells were used at early passages (passages 3-6). The cell purity of stromal cells was assessed by morphology and by immunostaining for vimentin. Following counting in the Neubauer chamber, the cell purity of the stromal cells was evaluated for morphology, and immunostaining with vimentin as a fibroblast marker, and with anti-proColXI $\alpha 1 \mathrm{mAb}$ (DMTX1, Oncomatryx) as a specific marker for human CAFs [16-18]. The remaining cells were frozen using DMEM $+10 \%$ FCS and 10\% DMSO as cryoprotectant in cryovials. The cryovials were maintained in $\mathrm{a}-80^{\circ} \mathrm{C}$ freezer overnight and then transferred into a liquid nitrogen container for long-term storage for other studies. Both types of cells (NF and CAFs), obtained from 3 patients, were seeded in six-well plates at a rate of $1 \times 10^{4}$ viable cells per well, using the culture medium previously used. Every 2 days, one of the dishes was trypsinized and the cells were counted on a Neubauer chamber. The wells were not filled in any case, so there was no contact inhibition.

142

\section{Colon adenocarcinoma cell line}

HT-29 cells (ATCC ${ }^{\circledR}$ HTB-38) were cultivated in DMEM standard media with 10\% FBS. All the cultures were carried out in a humidified atmosphere of $5 \% \mathrm{CO}_{2}$ in air at $37^{\circ} \mathrm{C}$. Culture passages and cell collections were done with trypsin/EDTA 0.05\%/0.02\% (Biochrom). 
149

150

151

152

153

154

155

156

157

158

159

160

161

162

163

164

165

166

167

168

169

170

171

172

173

174

175

176

177

178

179

180

181

182

183

184

185

186

187

188

The methodology used has been described previously [16]. In summary, cells were fixed in acetone, dried at room temperature, and then taken into the wash buffer. The samples were incubated with the anti-proColXI $\alpha 1 \mathrm{mAb}$, (DMTX1, Oncomatryx), Cytokeratin 19 (CK19) antibody, $\alpha$ SMA and VIM antibody, at room temperature, under the conditions specified in Table 1. The secondary antibodies used were green anti-rabbit Alexa-488 and red anti-rabbit Alexa-546, and the sections were mounted with mounting medium containing DAPI. The colocalization was visualized and photographed using a confocal microscope with specific sources of illumination for each fluorochrome excitation.

\section{Identification of human CAFs inside the pancreas of mice}

CAFs were labeled with PKH26 red fluorescence cell dye (Sigma-Aldrich PKH26 Red Fluorescent Cell Linker Kits for General Cell Membrane Labeling). The labeling vehicle provided in the kits (Diluent C) was designed to maintain cell viability, while maximizing dye solubility and staining efficiency during the labeling step. Due to it, cells present extremely stable fluorescence and PKH26 is the cell linker dye of choice for in vivo cell tracking studies. PKH26 consists of an aliphatic molecule that is incorporated into the cell membrane, linked to a rhodamine-like fluorescent dye. The optimum excitation wavelength is $551 \mathrm{~nm}$ and the emission wavelength is $567 \mathrm{~nm}$. The CAFs were injected into the pancreas of mice. After 7 days, mice were sacrificed and tumor samples were embedded in Tissue-Teck OCT (Thermo), and frozen in liquid nitrogen. Five-micrometer-thick sections were stored at $-80^{\circ} \mathrm{C}$. Sections were fixed in acetone $\left(-20^{\circ} \mathrm{C}, 10\right.$ minutes) and incubated with anti-proColXI $\alpha 1 \mathrm{mAb}$ (Oncomatryx, 1:400, 30 minutes)-secondary Alexa 488 (1:500, Invitrogen). Nuclei were counterstained with 4,6diamidino-2-phenylindole dihydrochloride hydrate (DAPI, Vector Labs). To document the presence and human origin of CAFs in tumor sections of mice, various sections per mouse were analyzed by confocal microscopy. PKH26 positive cells presented red fluorescence and proColXI $\alpha 1$ positive cells presented green fluorescence.

\section{Animals}

The transplants were done in immunodeficient male mice, BALB/cJHanHsd-Prdkcscid SCID strain, aged 4-10 weeks. They remained housed in a special room for immunodepressed mice, on a ventilated rack, and under a laminar flow hood used for handling.

\section{Transplants}

Inhalational anesthesia (isoflurane) and preoperative analgesia (intraperitoneal buprenorphine $0.05 \mathrm{mg} / \mathrm{kg} 15$ minutes prior to the intervention) were used. A $1-2 \mathrm{~cm}$ laparotomy was performed and the cell solution was slowly injected (30 seconds via a $30 \mathrm{G}$ needle, $50 \mu 1$ in PBS) into the head of the pancreas at the level of the pylorus. Following this procedure, meloxicam 1.5-2 mg/kg was administered intraperitoneally. The buprenorphine and meloxicam doses were repeated every $24 \mathrm{~h}$ during 2 days via the subcutaneous route. 
189 Experimental Design of Transplants

\section{Heterotopic transplant in the head of the pancreas of SCID mice}

191 A total of 34 mice were randomly distributed in four groups: I. 12 animals received 192 150,000 CAFs; IIa. In 7 mice 1.5 million HT29 cells were implanted; IIb. In 5 animals 150,000

$193 \mathrm{NF}$ and 1.5 million HT29 cells were transplanted; III. 10 mice received 150,000 CAFs and 1.5 194 million HT29 cells. To make sure that the CAFs transplants would not produce tumors on their 195 own, a greater number of animals were included in the group I. With the aim of removing any 196 potential defects in fibroblasts isolation, aliquots of the same isolated fibroblasts were 197 concurrently transplanted in all of the experimental groups. All the process were performed 198 under sterile conditions.

199

\section{Euthanasia}

At one-month post-transplant, the mice were euthanized using a $\mathrm{CO}_{2}$ chamber, and the intestinal and thoracic content removed in block, preserving them in $4 \%$ paraformaldehyde.

\section{Histological Analysis}

The samples were analyzed by personnel of the Department of Molecular Histopathology in Animal Cancer Models (University Institute of Oncology). Specimens were fixed for 24h in $4 \%$ paraformaldehyde at room temperature, embedded in paraffin, sectioned in sections of $5 \mu \mathrm{m}$ thickness, and stained with hematoxylin-eosin and anti-proColXIal mAb (DMTX1, Oncomatryx). The volume of the tumor which developed in the pancreas was calculated in $\mathrm{mm}^{3}$ with the formula major axis $X$ (minor axis) ${ }^{2} \times 0.53$. To assess the size of liver metastases, each liver was completely cut into serial sections with a distance between each section of $200 \mu \mathrm{m}$. The liver metastases were evaluated by counting the number that were observed in the histological sections, classifying their size in small, medium and large, giving to these a value of 1,2, or 3, respectively, as a measure of liver tumor burden. A small metastasis size was considered when the same tumor appeared in a single section $(\leq 400 \mu \mathrm{m})$, medium when the tumor appeared in two consecutive sections ( $>400 \mu \mathrm{m}$ and $\leq 600 \mu \mathrm{m}$ ), and large when the tumor appeared in three or more sections $(>600 \mu \mathrm{m})$. Hence, an animal with a liver containing one small metastasis, one medium and one large metastasis, was classified with a tumor burden of $6(1 \times 1+1 \times 2+1 \times 3=6)$.

We established a histopathological score system from 3 to 9 points, to compare the tumor severity or aggressiveness, based on three histopathological features (tumor volume, desmoplasia and number of metastasized organs) according to the following score: tumor volume feature was:1=small $\left(<50 \mathrm{~mm}^{3}\right) ; 2$ : medium $\left(50-150 \mathrm{~mm}^{3}\right)$ and $3=$ large $\left(>150 \mathrm{~mm}^{3}\right)$; the score given for desmoplasia was: $1=$ mild; $2=$ mild $/$ moderate, moderate; $3=$ moderate $/$ severe, and; the score given for number of metastasized organs was: $1=1-2$ organs; $2=3-4$ organs; $3=>4$ organs.

\section{Statistical Analysis}


Quantitative variables were expressed as medians. Groups were compared using the Mann-Whitney $U$ test. The association between quantitative variables was assessed using the regression coefficient and the prediction of one variable from another via the regression equation. The growth of the cell cultures was analyzed using ANOVA with Bonferroni correction. All analyses were performed using the programs SPSS 15.0 (SPSS, Inc., Chicago IL) for windows and MedCalvs12.

\section{Ethical Considerations}

All experiments complied with the European Union (2010/63/UE) and Spanish (RD 53/2013; ECC/556/2015) standards, and were in accordance with the guidelines of the Committee for the handling and care of animals of the University of Oviedo. The Committee for the handling and care of animals of the University of Oviedo provided full approval for this research (PROAE 01/2016). The patients signed consent forms indicating their willingness to participate in the study.

The extraction of surgical samples was approved by the Hospital Universitario Central de Asturias ethical committee (Project $n^{\circ}$ 42/12).

\section{Results}

\section{Characterization of the Colon Adenocarcinoma CAFs}

The fibroblasts for transplantation had positive immunostaining to proColXI $\alpha 1$ (Fig.S1). Using confocal microscopy, the CAFs and NF cultured were proColXI $\alpha 1+/ \mathrm{VIM}+$, proColXIa1+/alphaSMA+ and a small number of cells with the epithelial phenotype (proColXI $1+/ \mathrm{CK} 19+$ ) (Fig. 1). Figure S2 shows the coexpression in the peritumoral area of carcinoma in mouse heterotopic xenogratfs of the PKH-26 dye and human proColXI $\alpha 1$ in CAFs. The CAFs growth curve was significantly larger than that of the NF $(p<0.05)$ (Fig.2). The details of data collected in growth curves are depicted in Table Supplementary S1 in which the number of cells obtained in each well is represented as the mean of two determinations. The CAFs growth curve was significantly larger than that of NF ( $p<0.05)$ (Fig. 2).

\section{Xenotransplants}

No tumor developed in those animals that only received CAFs (Table 2). Of the animals that received HT29 cells without fibroblasts, 5 died in the initial days following the procedure. The surviving two mice presented with poorly differentiated carcinomas in the pancreas with light dysplasia, infiltrating the stomach due to proximity, and liver metastases; lung metastases also developed in one of the mice in which a focus was also found in the small intestine (Fig. 3, 
264 Table S2)). Of the five mice that received HT29 + NF, one died; the remaining four developed a

265

266

267

268

269

270

271

272

273

274

275

276

277

278

279

280

281

282

283

284

285

286

287

288

289

290

291

292

293

294

295

296

297

298

299

300

301 tumor with liver metastases, and one had multiple lung and spleen metastases (Fig. 4, Table S3). They all showed occasional tumor foci in the small and large bowel.

Of the ten animals in the HT29 + CAFs group, two died and one did not develop tumor. The tumor volume in the pancreas was significantly bigger than in the combined group that received HT29 with/without NF. All cases with tumor in the pancreas developed liver metastases with a higher tumor burden than in the other transplant groups, but without reaching statistical significance, and in more than half lung metastases were identified. One animal presented with metastases in the spleen, four in the small intestine, and two in the peritoneum with multiple foci of lymphovascular invasion (Fig. 5, S3; Table S4).

The cytological pattern of all of these showed cell and nuclear pleomorphism, with an increase in the nuclear-cytoplasmic ratio, irregular nuclear membranes, and various nucleoli. The histological pattern of the mice that received fibroblasts or CAFs was that of moderately or poorly differentiated carcinoma, with low-moderate dysplasia, some with vascular invasion, and infiltrating the stomach due to proximity.

Median hepatic nodules, tumor burden, lung metastases and severity score were bigger in group III vs group II, although without being significant, except in the case of the median tumor volume, that was significantly higher in group III $\left(154.8(76.9-563.2) \mathrm{mm}^{3}\right)$ vs group II (46.7 (3.7-239.6) $\left.\mathrm{mm}^{3}\right), p=0.04$. A relationship was observed between the size of the tumor developed in the pancreas and the metastatic tumor burden in the liver $(\mathrm{y}=0.321+4.483 \log (\mathrm{x}), \mathrm{r}=0.69, \mathrm{P}$ $=0.001)$ and the severity score $(\mathrm{y}=2.231+2.008 \log (\mathrm{x}), \mathrm{r}=0.79, \mathrm{P}<0.001$ (Fig. 6).

\section{Discussion}

The possibility of personalized cancer treatment is affected by the heterogeneity of the primary tumor and that of the metastases, which means that the results of gene and molecular expression obtained from one area of the tumor are different from those in other areas of the same tumor, and therefore the behavior cannot be determined from a few biopsies [19]. In an attempt to simulate the human disease in animals and in order to be able to apply new treatments, different animal models of cancer have been made [20, 21]. Animal that have been genetically modified for this purpose, GEMM, may shed light on the role of different genes in the appearance of this disease. In one of these animal models, it was demonstrated that cancer metastases precede the formation of the primary tumor [22], which would be in line with the hypothesis that cancer is a systemic disease from the start; this is further supported by findings of metastases in patients without being able to localize the primary tumor. The main disadvantage of these models is that the alterations affect the germ line, resulting in the possible development of diseases from the embryonic stage. Furthermore, they develop precancerous or cancerous lesions at other levels [20]. 
302

303

304

305

306

307

308

309

310

311

312

313

314

315

316

317

318

319

320

321

322

323

324

325

326

327

328

329

330

331

332

333

334

335

336

337

338

339

340

341

The initial control of the tumor is an advantage in chemically induced cancers or cancers induced via implantation of tumor cells $[20,23]$. In terms of the administration of carcinogenic substances, the process depends on the duration and dose, and the state of the organism [23]. One general limitation of these experiments is the scarce development of metastases [20].

The model most utilized by researchers to trial new treatments is the xenotransplant of cancerous human cells in immunodepressed animals, usually SCID mice or other variants, either in the organ where the tumor develops — orthotopic xenotransplant - or in another anatomic region such as subcutaneous tissue-heterotopic xenotransplant. An important limitation of this model is that it lacks the influence that part of the immune system has on the development of the xenotransplant. In xenotransplants, tumor cell lines or slices of tumor samples extracted from patients, PDX (patient derived xenograft), are used. These samples are obtained fresh from tumor and should be implanted as soon as possible within the first 24 hours [6, 24]. PDX has the advantage that the animal receives the full tumor repertoire from the patient: tumor and the peritumoral inflammatory reaction [25]. Additionally, these would be appropriate to trial personalized treatments: the patient's tumor is transplanted in a series of animals that are treated with diverse drugs, and the one which best controls the tumor would be used in the patient [26, 27]. Nevertheless, this method has its limitations as well: it requires the use of animals that lack an immune system, the stroma that forms is murine and not human, and sometimes does not develop metastases [25]. In addition, its clinical use is not without difficulties: with slow tumor growth, it is transferred to other animals to have a sufficient number for treatments, need for controls, and costs involved.

One of the primary surgical models developed was the heterotopic transplant conducted in subcutaneous tissue of immunodeficient mice and implanted with human colon cancer cells. In this model, the growth was easily monitored, however, being situated extra-abdominally, did not develop metastases [28]. Some authors have utilized this technique as a step prior to conducting an orthotopic transplant, using the subcutaneous tumor to obtain samples that are then implanted in the colon of other mice [28-30]. The splenic capsule and kidney are also used as sites for implantation [28]. The orthotopic model is considered the one that best simulates the process of human colon cancer development [28].

In recent years organoids have been developed, which are bodies of cells cultivated in vitro forming a three-dimensional structure. Their functional and anatomic characteristics are more like the original organ. They are made from healthy and tumor stem cells, which allows for the study of its behavior and reaction to drugs in both cases [31].

To avoid the inconvenience of the scarce tumor appearance, slow development, absence of metastases, and economic cost, that the aforementioned models present, we have trialed a new xenotransplant model that consists of implanting CAFs obtained from fresh colon cancer specimens conjointly with HT-29 tumor cells in SCID mice. This model is very aggressive, and within a few weeks develops a large tumor with liver metastases, and therefore it is possible to start new treatments without delay. Our team has focused its research on CAFs [16-18, 32], and on a protein from the collagen family, collagenXI $\alpha 1$, which is universally overexpressed in the 
342 stroma of epithelial tumors [33], namely in the cytoplasm of the CAFs and not in the epithelial

343 cells. The antibody anti-proColXI $\alpha 1$ stains CAFs specifically [18], in contrast to other

344 mesenchymal markers such as vimentin and $\alpha$ SMA that stains a wide variety of fibroblasts,

345 including normal fibroblasts, fibroblasts from inflammatory areas, and in lesions, etc. In tissue,

346 whereas non-peritumoral fibroblasts are stained with anti-vimentin and anti $\alpha \mathrm{SMA}$, the CAFs are

347 also stained with anti-proColXIa1; nevertheless, in cultures these differences in the expression of

348 markers between the different groups disappear. In a pancreatic cancer model, cultivating

349 fibroblasts from CAPAN-1 cells, a higher proliferation of these cells was observed in the

350 presence of peritumoral fibroblasts compared with non-tumor fibroblasts or without the presence

351 of fibroblasts [15]; which would be consistent with the results of the xenotransplants associated

352 with the CAFs. The human fibroblasts transplanted in animals can be visualized using anti-

353 proColXI $\alpha 1$ and be distinguished from those of the animals, as this antibody is specifically

354 human and does not cross-react with other species [34], which would allow the monitoring over

355 time of these cells in the animal. Another feature of anti-proColXI $\alpha 1$ is that it marks cells that

356 are in epithelial-mesenchymal transition showing double staining for epithelial (CK19) and

357 mesenchymal (vimentin) [16].

358 The resulting cultured cells in our experiments were fibroblasts both morphologically and

359 in terms of their phenotypic characteristics, staining for non-specific mesenchymal markers such

360 as vimentin; specific markers of inflammation, such as smooth muscle alpha-actin; and, as well

361 as the specific marker for CAFs, procollagenXI $\alpha 1$. The percentage of mesenchymal cells marked

362 exclusively with CK19 was scarce, although it was possible to observe cells with a double

363 phenotype procollagenXI $\alpha 1+/ \mathrm{CK} 19+$, characteristic of cells in epithelial-mesenchymal

364 transition. As our samples of CAFs were not significantly contaminated with tumor cells, this

365 shows why the transplants conducted with only fibroblasts did not develop any tumor. In other

366 models of xenotransplants, tumor did not develop either with the administration of CAFs [35,36].

367 The fibroblasts of normal tissue did not stain for SMA nor for procollagenXI 1 ; however, under

368 the artificial conditions of the culture, some fibroblasts obtained from non-tumor areas acquired

369 positivity for those markers due to the artificial conditions to which they had been subjected.

370

371

According to the hypothesis that the tumor stroma, and fibroblasts in particular, promote

progession, we coupled CAFs cultivated from our surgical samples with HT29 cells in

372 this new transplant model and chose the pancreas as the implantation site, as in this organ very

373 aggressive tumors develop with a high metastatic capacity and high mortality. This is due to

374 various mechanisms, among which are the influence of the substances secreted by the pancreatic

375 islets that stimulate cell growth [37]. In our research group, models of pancreatic cancer have

376 been developed previously [15]. Given our training in this technique we decided to apply the

377 heterotopic model of colon cancer. We conducted a control group with CAFs transplant without

378 tumor cells to verify that these cells alone are not capable of developing tumor. In the subsequent

379 experimental groups, cell lines of colon cancer were transplanted, alone and coupled with NF or

380 CAFs. In both models, tumors and multiple metastases were obtained, with the group including

381 CAFs producing the largest size tumors. 
382

383

384

\section{Conclusions}

386

387

388

389

390

391

392

393

394

395

396

397

398

399

400

401

402

403

404

405

406

407

408

409

410 3. Scientific American Surgery. 2016. Gastrointestinal Tract \& Abdomen Surgery. Volumen 411 2. Adenocarcinoma de colon y recto. Barcelona: Continuing Medical Communication S.L.

412 4. Sociedad Española de Oncología Médica (SEOM). 2017. Las cifras del Cáncer en España 413 en 2017.

at

414 https://seom.org/seomcms/images/stories/recursos/Las_cifras_del_cancer_en_Esp_2017.pdf

415 (accessed 20 June 2018).

416 5. Asociación Española contra el Cáncer. 2018. Cáncer de Colon. Available at 417 https://www.aecc.es/SobreElCancer/CancerPorLocalizacion/cancerdecolon/Paginas/incidencia.as 418 px. 
419 6. Rashidi B, Sun FX, Jiang P, An Z, Gamagami R, Moossa AR, Hoffman R. 2000. A 420 nude model of massive liver and lymph node metastasis of human colon cancer. Anticancer 421 research, 20:715-722.

422 7. Roy S. Majumdar A. 2012. Signaling in colon cancer stem cells. Journal of molecular 423 signaling, 7:11. DOI: 10.1186/1750-2187-7-11.

424 8. van Pelt GW, Sandberg TP, Morreau H, Gelderblom H, van Krieken JHJM, Tollenaar 425 RAEM, Mesker WE. 2018. The tumour-stroma ratio in colon cancer: the biological role and its 426 prognostic impact. Histopathology, 73:197-206. DOI: 10.1111/his.13489. Epub 2018 Mar 24.

427 9. Mukaida N, Sasaki S. 2016. Fibroblasts, an inconspicuous but essential player in colon 428 cancer development and progression. World journal of gastroenterology, 22: 5301-5316. doi: 429 10.3748/wjg.v22.i23.5301.

430 10. Kalluri R. 2016. The biology and function of fibroblasts in cancer. Nature reviews. 431 Cancer, Aug 23;16(9):582-98. doi: 10.1038/nrc.2016.73.

432 11. Valcz G, Sipos F, Tulassay Z, Molnar B, Yagi Y. 2014. Importance of carcinoma433 associated fibroblast-derived proteins in clinical oncology. Journal of clinical pathology, 434 67:1026-31. DOI: 10.1136/jclinpath-2014-202561. Epub 2014 Aug 18.

435 12. Huang L, Xu AM, Liu S, Liu W, Li TJ. 2014. Cancer-associated fibroblasts in digestive 436 tumors. World journal of gastroenterology, 20:17804-18. DOI: 10.3748/wjg.v20.i47.17804.

437 13. Öhlund D, Elyada E, Tuveson D. 2014. Fibroblast heterogeneity in the cancer wound. 438 The Journal of experimental medicine, 211:1503-23. DOI: 10.1084/jem.20140692.

439 14. Whittle MC, Hingorani SR. 2019. Fibroblasts in Pancreatic Ductal Adenocarcinoma: 440 Biological Mechanisms and Therapeutic Targets. Gastroenterology,156:2085-2096. DOI: 441 10.1053/j.gastro.2018.12.044. Epub 2019 Feb 2.

442 15. Porrero Guerrero B. 2017. Papel de los fibroblastos peritumorales en la progresión del 443 cáncer de páncreas humano: estudio del gen erizo. Thesis, Oviedo University.

444 16. García Pravia C, Galván JA, Gutiérrez Corral N, Solar García L, García Pérez E, García 445 Ocaña M, Del Amo Iribarren J, Menéndez Rodríguez P, García García J, de los Toyos JR, Simón 446 Buela L, Barneo L. 2013. Overexpression of COL11A1 by cancer-associated fibroblasts: clinical 447 relevance of a stromal marker in pancreatic cancer. PloS one, 8:e78327. DOI: 448 10.1371/journal.pone.0078327. eCollection 2013.

449 17. Galván JA, García Martínez J, Vázquez Villa F, García Ocaña M, García Pravia C, 450 Menéndez Rodríguez P, González del Rey C, Barneo Serra L, de los Toyos JR. 2014. Validation 451 of COL11A1/procollagen 11A1 expression in TGF-B1-activated immortalised human 452 mesenchymal cells and in stromal cells of human colon adenocarcinoma. BioMed Central 453 Cancer, 14:867. DOI:10.1186/1471-2407-14-867.

454 18. García-Ocaña M, Vázquez F, García-Pravia C, Fuentes-Martínez N, Menéndez455 Rodríguez P, Fresno-Forcelledo F, Barneo-Serra L, Del Amo-Iribarren J, Simón-Buela L, R. De 456 los Toyos J. 2012. Characterization of a novel mouse monoclonal antibody, clone 1E8.33, highly 457 specific for human procollagen 11A1, a tumor associated stromal component. International 458 journal of oncology, 40: 1447-1454. DOI: 10.3892/ijo.2012.1360. Epub 2012 Feb 7. 
459 19. Gerlinger M,Rowan AJ, Horswell S, Math M, Larkin J, Endesfelder D, Gronroos E, 460 Martinez P, Matthews N, Stewart A, Tarpey P, Varela I, Phillimore B, Begum S, McDonald NQ, 461 Butler A, Jones D, Raine K, Latimer C, Santos CR, Nohadani M, Eklund AC, Spencer-Dene B, 462 Clark G, Pickering L, Stamp G, Gore M, Szallasi Z, Downward J, Futreal PA, Swanton C. 2012. 463 Intratumor heterogeneity and branched evolution revealed by multiregion sequencing. The New 464 England journal of medicine, 366:883-892. DOI: 10.1056/NEJMoa1113205.

465 20. Johnson RL, Fleet JC. 2013. Animal Models of Colorectal Cancer. Cancer Metastasis 466 Reviews, 32: 39-61. DOI:10.1007/s10555-012-9404-6.

467 21. Taketo MM, Edelmann W. 2009. Mouse models of colon cancer. Gastroenterology, 136: 468 780-798. DOI:10.1053/j.gastro.2008.12.049.

469 22. Rhim AD, Mirek ET, Aiello NM, Maitra A, Bailey JM, McAllister F, Reichert M, Beatty 470 GL, Rustgi AK, Vonderheide RH, Leach SD, Stanger BZ. 2012. EMT and dissemination precede 471 pancreatic tumor formation. Cell, 148:349-61. DOI:10.1016/j.cell.2011.11.025.

472 23. Karim BO, Huso DL. 2013. Mouse models for colorectal cancer. American journal of 473 cancer research, 3: 240-250.

474 24. Fu XY, Besterman JM, Monosov A, Hoffman RM. 1991. Models of human metastatic 475 colon cancer in nude mice orthotopically constructed by using histologically intact patient 476 specimens. Proceedings of the National Academy of Sciences of the United States of America, 477 88: 9345-9. DOI: 10.1073/pnas.88.20.9345.

478 25. Katsiampoura A, Raghav K, Jiang ZQ, Menter DG, Varkaris A, Morelli MP, Manuel S, 479 Wu J, Sorokin AV, Rizi BS, Bristow C, Tian F, Airhart S, Cheng M, Broom BM, Morris J, 480 Overman MJ, Powis G, Kopetz S. 2017. Modeling of Patient-Derived Xenografts in Colorectal 481 Cancer. Molecular cancer therapeutics, 16:1435-1442. DOI: 10.1158/1535-7163.MCT-16-0721. 482 Epub 2017 May 3.

483 26. Okada S, Vaeteewoottacharn K, Kariya R. 2018. Establishment of a Patient-Derived 484 Tumor Xenograft Model and Application for Precision Cancer Medicine. Chemical \& 485 pharmaceutical bulletin, 66:225-230. DOI: 10.1248/cpb.c17-00789.

486 27. Williams JA. 2018. Using PDX for Preclinical Cancer Drug Discovery: The Evolving 487 Field. Journal of clinical medicine, 7:41. DOI: 10.3390/jcm7030041.

488 28. Mittal VK, Bhullar JS, Bhullar JS, Jayant K. 2015. Animal models of human colorectal 489 cancer: Current status, uses and limitations. World journal of gastroenterology, 21: 11854490 11861. doi: 10.3748/wjg.v21.i41.11854.

491 29. Flatmark K, Maelandsmo GM, Martinsen M, Rasmussen H, Fodstad Ø. 2004. Twelve 492 colorectal cancer cell lines exhibit highly variable growth and metastatic capacities in an 493 orthotopic model in nude mice. European journal of cancer, 40: 1593-1598. 494 DOI:10.1016/j.ejca.2004.02.023.

495 30. Fodstad O. 1991. Tumorigenicity and dissemination of human tumors in congenitally 496 immune-deficient mice. Journal of the National Cancer Institute, 83: 1419-1420. 497 DOI:10.1093/jnci/83.19.1419. 
498 31. Young M, Reed K. 2016. Organoids as a model for colorectal cancer. Current colorectal

499

500

501

502

503

504

505

506

507

508

509

510

511

512

513

514

515

516

517

518

519

520

521

522

523

524

525

526

527

528

529

530

531

532

533

cancer reports, 12:281-287. DOI:10.1007/s11888-016-0335-4.

32. Fuentes Martínez N, García Pravia C, García Ocaña M, Menéndez Rodríguez P, Del Amo J, Suárez Fernández L, Galván JA, De los Toyos JR, Barneo L. 2015. Overexpression of proCOL11A1 as a stromal marker of breast cancer. Histology and histopathology, 30:87-93. DOI: 10.14670/HH-30.87. Epub 2014 Jul 9.

33. Vázquez Villa F, García Ocaña M, Galván JA, García Martínez J, García Pravia C, Menéndez Rodríguez P, González del Rey C, Barneo Serra L, de Los Toyos JR. 2015. COL11A1/(pro)collagen 11A1 expression is a remarkable biomarker of human invasive carcinoma-associate stromal cells and carcinoma progression. Tumour biology : the journal of the International Society for Oncodevelopmental Biology and Medicine, 36:2213-22. DOI: 10.1007/s13277-015-3295-4. Epub 2015 Mar 12.

34. Fernández-García MT, Vázquez-Villa JF, García-Martínez J, Sánchez-Pitiot M, CentenoRamos I, Fernando-Macías E, Porrero-Guerrero B, López-Arévalo C, Barneo L. 2014. ProCol11A1 expression in human peritumoral fibroblasts in model of orthotopic human pancreatic carcinoma xenograft. [Abstract] British Journal of Surgery (Suppl 1): 5-5

35. Porrero Guerrero B, Vazquez Villa JF, Fernández García MT, Fernando Macías E, Arévalo López C, García Pérez E, Suarez Fernández L, García De La Fuente V, Gómez Pinillos V, García Pravia C, García Ocaña M, De los Toyos JR, Barneo Serra L. 2015. Influence of mesenchymal cells at the tumor growth in a model animal orthotopic xenograft of human pancreatic adenocarcinoma. [Abstract] Abstracts of the 20th Congress of the Spanish Society for Surgical Research, Albacete, October 2014, British Journal of Surgery (Suppl 1): 1-26.

36. Rodríguez Uría R, Fernando Macías E, Fernandez García MT, Muñiz Salgueiro MC, Vazquez Villa JF, Porrero Guerrero B, López-Arevalo CA, Sanz Navarro S, Barneo Caragol C, Barneo Serra L. 2018. Mesenchymal cells use as an alternative to peritumoral fibroblasts for the study of tumor growth in an animal model of human pancreatic adenocarcinoma. [Abstract] Abstracts of the 23rd Congress of the Spanish Society for Surgical Research, Madrid, November 2017. British Journal of Surgery (Suppl 2): 5-14.

37. Kim SK, Herbrok M. 2001. Intercellular signals regulating pancreas development and function. Genes \& development, 15: 111-27. DOI:10.1101/gad.859401.

38. Porrero Guerrero B, López Arévalo C, Fernando Macias E, Ugalde Serrano P, García Pérez E, Suárez Fernández L, Galván Hernández JA, Vázquez Villa JF, Castro Santos P, de los Toyos González JR, González del Rey MC, Menéndez Rodríguez MP, García Pravia C, Barneo Serra L. 2013. A new model of orthotopic human pancreatic carcinoma xenograft. [Abstract] Abstracts of the 18th Congress of the Spanish Society for Surgical Investigations, Leon, October 2012. British Journal of Surgery (Suppl 1): 1-20.

Peer) reviewing PDF | (2019:11:43013:1:1:REVIEW 12 Mar 2020) 


\section{Table 1 (on next page)}

Summary of antibodies used for immunocytochemistry (IHC)

mAb: Monoclonal antibody. pAb: Polyclonal antibody 
Table 1. Summary of antibodies used for immunocytochemistry (IHC)

\begin{tabular}{|c|c|c|c|c|}
\hline $\begin{array}{l}\text { Primary } \\
\text { antibodies } \\
\text { (species) }\end{array}$ & Clone & $\begin{array}{l}\text { Commercial } \\
\text { reference }\end{array}$ & Dilution & $\begin{array}{l}\text { Incubation time } \\
\text { (min) }\end{array}$ \\
\hline $\begin{array}{l}\text { anti- } \\
\text { procollagenXI } \alpha 1 \\
(\mathrm{mAb})\end{array}$ & $\begin{array}{l}\text { 1E8.33RCK10 } \\
8\end{array}$ & $\begin{array}{l}\text { DMTX1/Oncomatry, } \\
\text { Spain }\end{array}$ & $1: 400$ & 30 \\
\hline CK 19 (mAb) & RCK108 & Dako, Denmark & $1: 50$ & 15 \\
\hline$\alpha-S M A(m A b)$ & $1 \mathrm{~A} 4$ & Dako, Denmark & Ready to use & 20 \\
\hline Vimentin (pAb) & $\mathrm{C}-20$ & $\begin{array}{l}\text { Santa Cruz Biotech, } \\
\text { Germany }\end{array}$ & $1: 400$ & 10 \\
\hline
\end{tabular}

mAb: Monoclonal antibody. pAb: Polyclonal antibody 


\section{Table 2 (on next page)}

Summary of results in xenografts

*Bold italyc: HT29 +NF values. Liver tumor burden and severity score: see text 
Table 2. Summary of results in xenografts

\begin{tabular}{|c|c|c|c|c|}
\hline & I. CAFs & II. HT29, HT29NF* & III. HT-29 CAFs & P III vs II \\
\hline No. animals & 12 & $12(7+5)$ & 10 & \\
\hline Exitus & 0 & $6(5+1)$ & 2 & \\
\hline Tumor incidence (\%) & 0 & $\begin{array}{l}100 \\
(6 / 6)\end{array}$ & $\begin{array}{l}87.5 \\
(7 / 8)\end{array}$ & NS \\
\hline Tumor volume $\left(\mathrm{mm}^{3}\right)$ & - & $\begin{array}{l}3.7 ; 91.6 \\
8 ; 28.2 ; 65.3 ; \\
239.6\end{array}$ & $\begin{array}{l}76.9 ; 93.7 ; 143.9 ; \\
154.8 ; 169.9 ; \\
207 ; 563.6\end{array}$ & \\
\hline $\begin{array}{l}\text { Median tumor volume } \\
\left(\mathrm{mm}^{3}\right)\end{array}$ & - & $\begin{array}{l}46.7 \\
(3.7-239.6)\end{array}$ & $\begin{array}{l}154.8 \\
(76.9-563.2)\end{array}$ & 0.04 \\
\hline Hepatic metastases (\%) & - & $100(6 / 6)$ & $100(7 / 7)$ & \\
\hline No. hepatic nodules & & $\begin{array}{l}1 ; 6 \\
2 ; 3 ; 4 ; 5\end{array}$ & $6 ; 9 ; 9 ; 10 ; 14 ; 14$ & \\
\hline $\begin{array}{l}\text { Median hepatic nodules } \\
\text { (min - max) }\end{array}$ & & $\begin{array}{l}3,5 \\
(1-6)\end{array}$ & $\begin{array}{l}6 \\
(2-11)\end{array}$ & 0.12 \\
\hline $\begin{array}{l}\text { Median tumor burden } \\
\text { (min - max) }\end{array}$ & & $\begin{array}{l}6.5 \\
(1-12)\end{array}$ & $\begin{array}{l}10 \\
(6-15)\end{array}$ & 0.08 \\
\hline Lung metastases (\%) & - & $33(2 / 6)$ & $57(4 / 7)$ & NS \\
\hline Severity score (min - max) & & $5(3-8)$ & $7(5-8)$ & 0.06 \\
\hline
\end{tabular}

*Bold italyc: HT29 +NF values. Liver tumor burden and severity score: see text 


\section{Figure 1}

Confocal microscopy of cultured CAFs

Double fluorecence stain illustrate the presence of: (A) Cell proCOL11A1+/NIM+, (B) ProCOL11AQ1+/CK19+ and (C) ProCOL11A1+/alphaSMA+. Red: proCOL11A1; green: VIM, alphaSMA and CK19; blue: nuclei. Scale bar: figures A, B: $20 \mu \mathrm{m}$, figure C: $100 \mu \mathrm{m}($ X630).

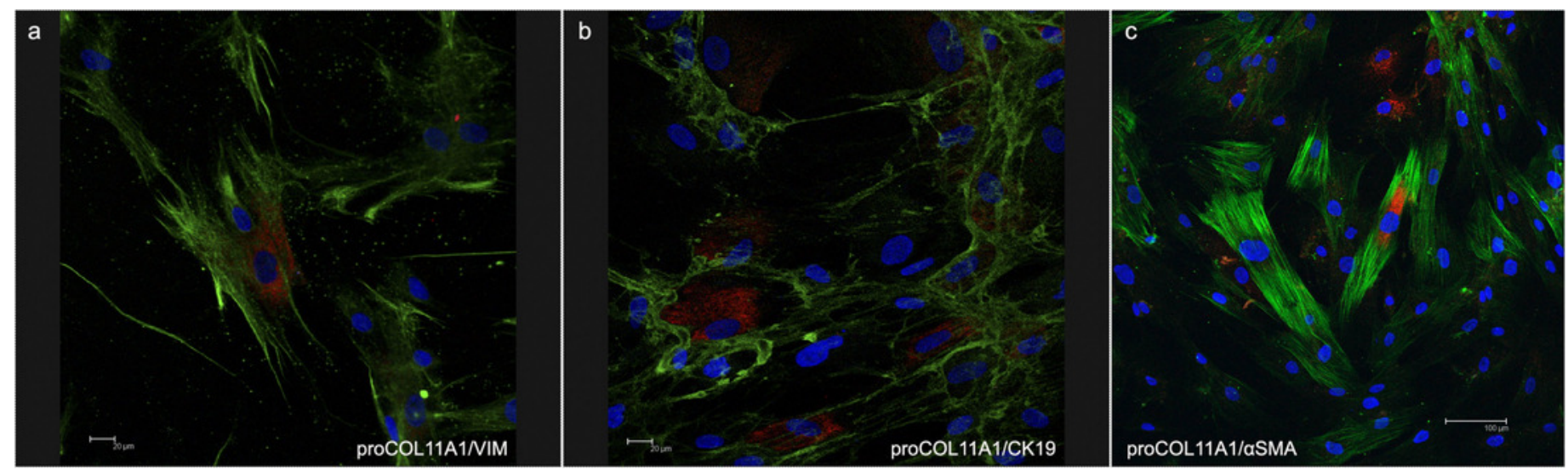


Figure 2

\section{Growth curves of fibroblasts}

Blue, normal fibroblasts; green, CAFs. Cultures obtained from three patients with adenocarcinoma of colon. Mean \pm 2 SEM of three patiens with duplicate determinations.

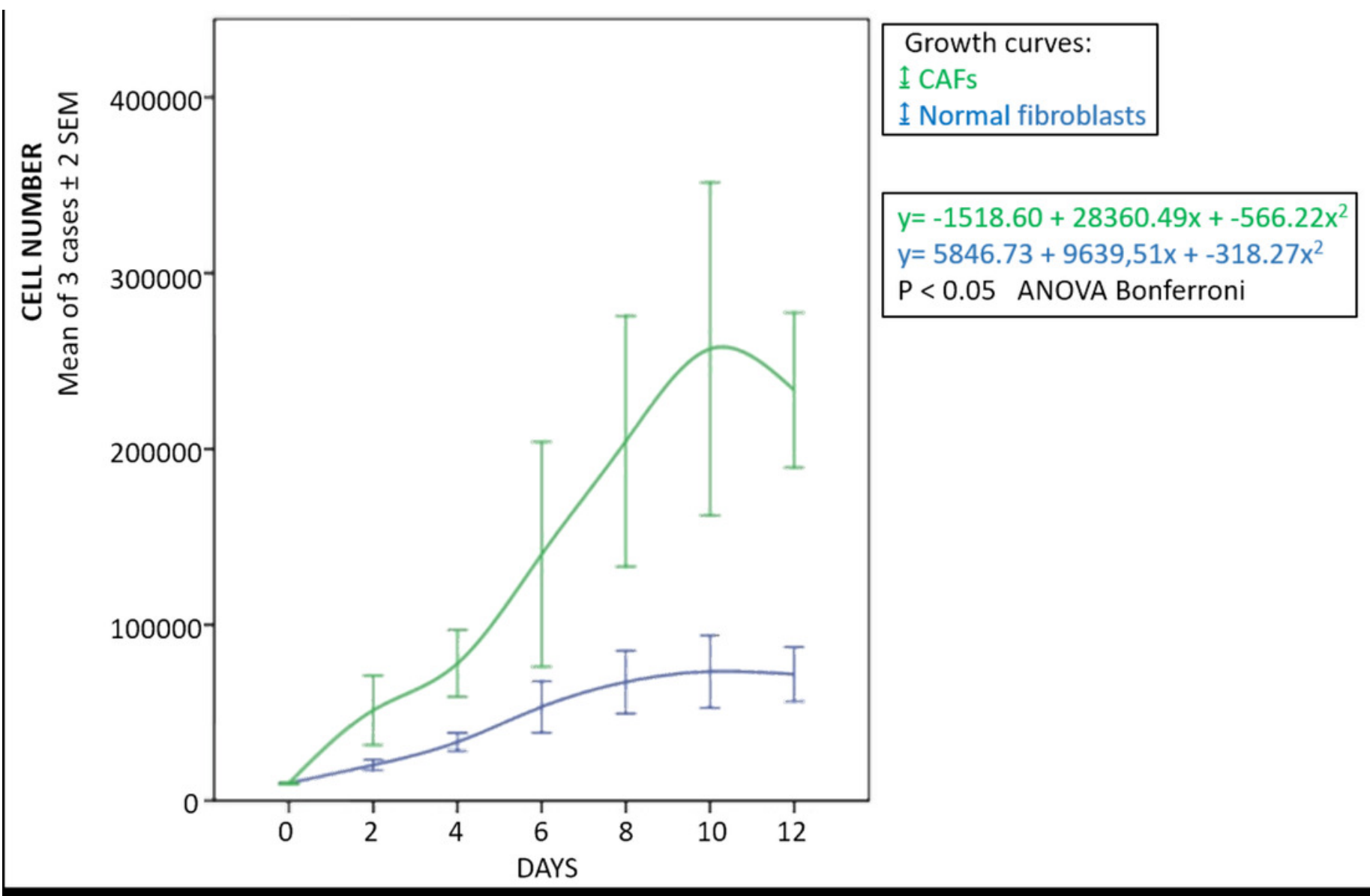




\section{Figure 3}

HT-29 in the pancreas model

(A) Microphotograph of maximal tumor size in pancreatic tissue (maximal tumor size, score 1) 1,25X, H-E. Red circle: maximal tumor size in pancreatic tissue. (B) Histological image of poorly differentiated pancreatic adenocarcinoma, 10x, H-E. Malignant epithelial cells isolated or arranged in small or large clusters, with mild-moderate desmoplastic stromal reaction (score 2). (C) The image shows metastasis of a small cluster of malignant epithelial cells (score 1 of $N$ o of metastasized organs) in: $\mathbf{C}=$ liver tissue; $\mathbf{D}=$ lung tissue. ( $\mathrm{H}-\mathrm{E}, 4 \mathrm{x})$. Red circle figures $\mathbf{C}$ and $\mathbf{D}$ : nest of tumoral cells in liver and lung, respectively. Scale bar: figure A: $500 \mu \mathrm{m}$; figure B, D: $50 \mu \mathrm{m}$; figure c: $200 \mu \mathrm{m}$. 


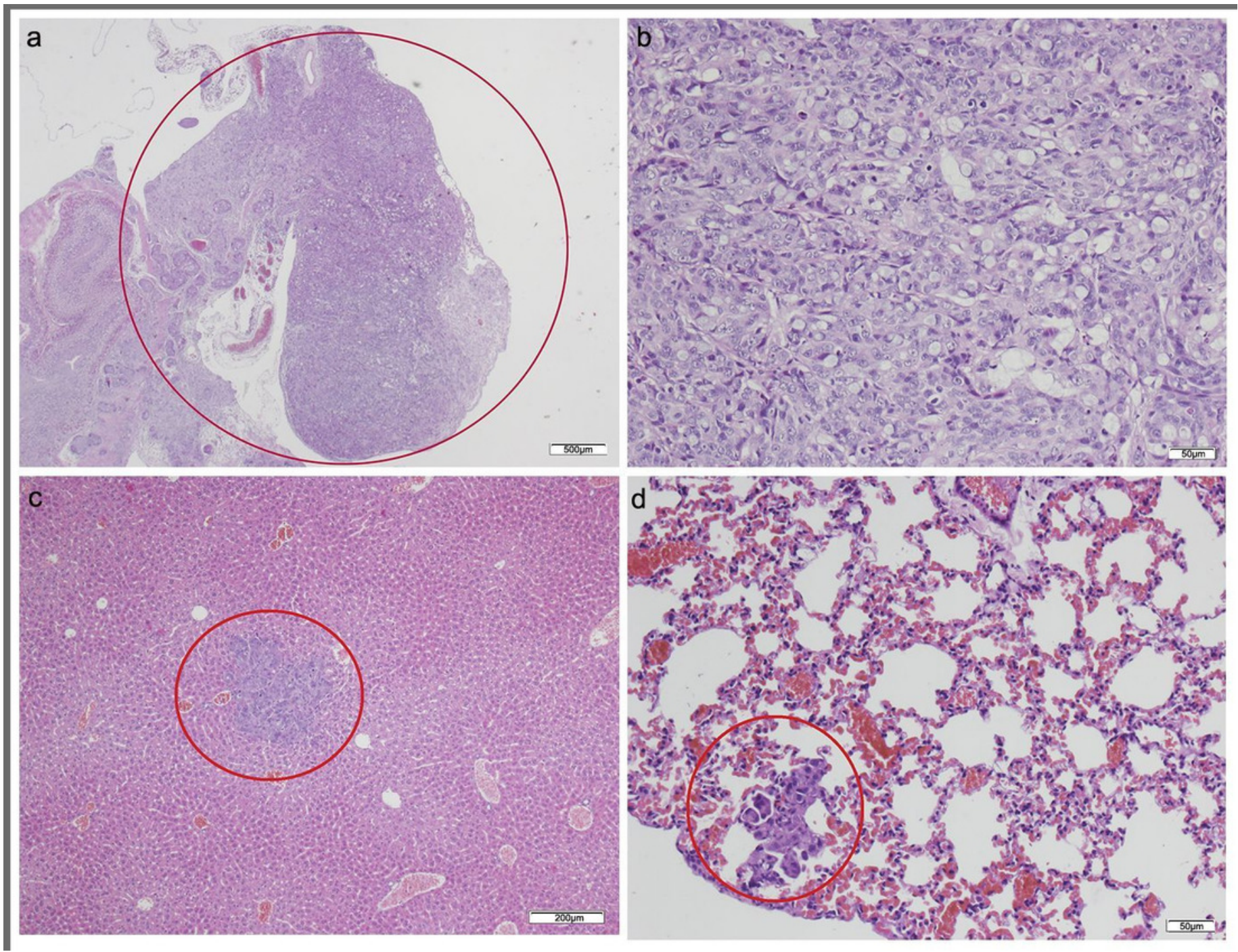




\section{Figure 4}

HT29 + NF

(A) Mouse necropsy. Great pancreatic tumor distention gallbladder (Courvoisier-Terrier signe), gastric infiltration. (B) Microphotograph of maximal tumor size in pancreatic tissue (maximal tumor size, score 2) 1,25x, H-E. (C) The image shows metastasis of small or medium clusters of malignant epithelial cells (score 1 of $N$ o of metastasized organs) in: $\mathbf{C}=$ liver tissue; $\mathbf{D}=$ lung tissue. (H-E, $4 \mathrm{x})$. Scale bar: figure $\mathbf{B}$ : $500 \mu \mathrm{m}$; figure $\mathbf{C}$ : $200 \mu \mathrm{m}$; figure $\mathbf{D}$ : $50 \mu \mathrm{m}$.
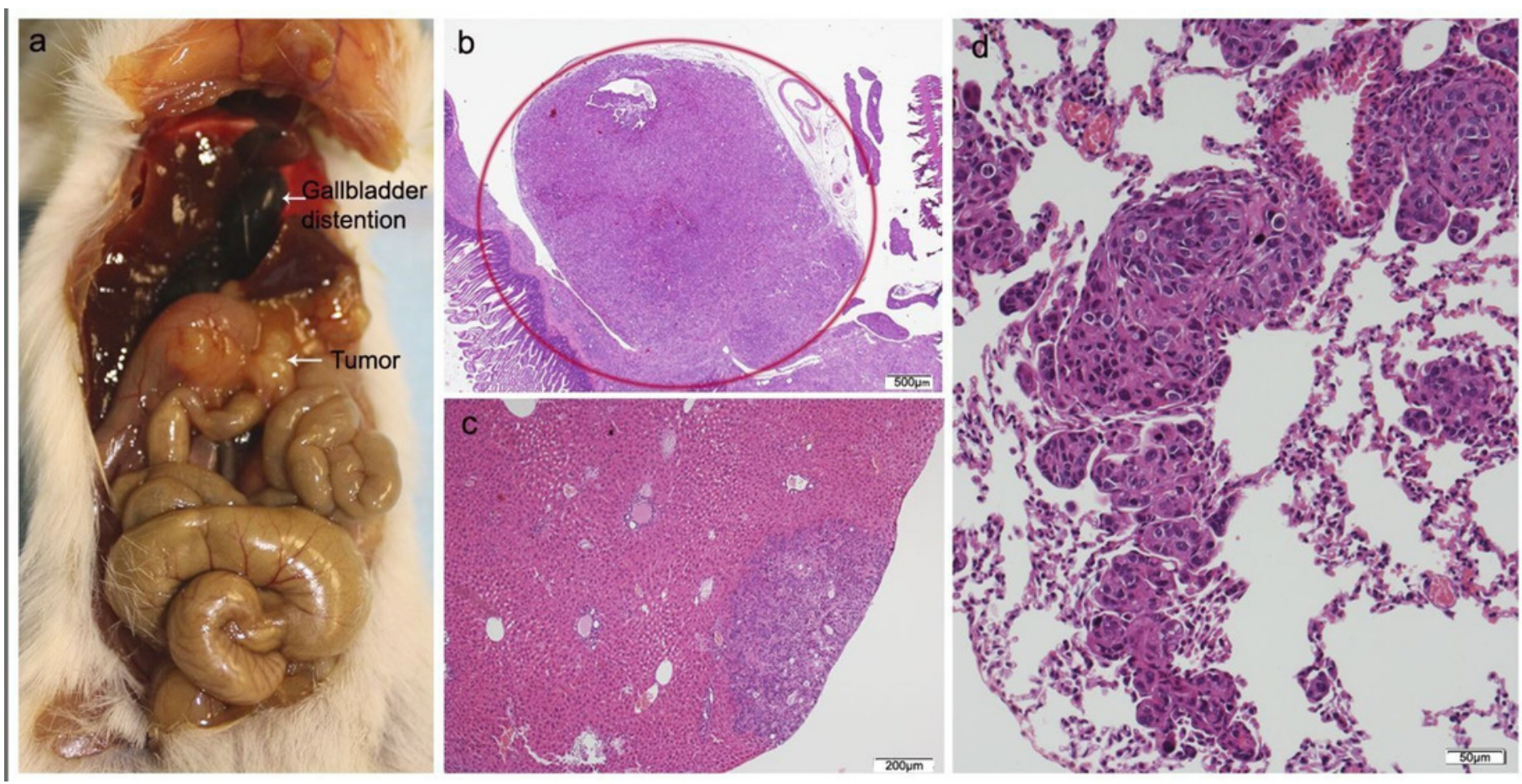


\section{Figure 5}

\section{HT29 + CAFs}

(A) Mouse necropsy. Great pancreatic tumor with liver metastases, distention gallbladder (Courvoisier-Terrier signe), gastric infiltration. (B) Microphotograph of maximal tumor size in pancreatic tissue (maximal tumor size, score 3) 1,25x, H-E. Red circle: maximal tumor size in pancreatic tissue. (C) Histological image of poorly differentiated pancreatic adenocarcinoma, 10x, H-E. Malignant epithelial cells isolated or arranged in small or large clusters, with necrosis and moderate desmoplastic stromal reaction (score 2). Scale bar: figure B: $500 \mu m$; figure C: $50 \mu \mathrm{m}$. 

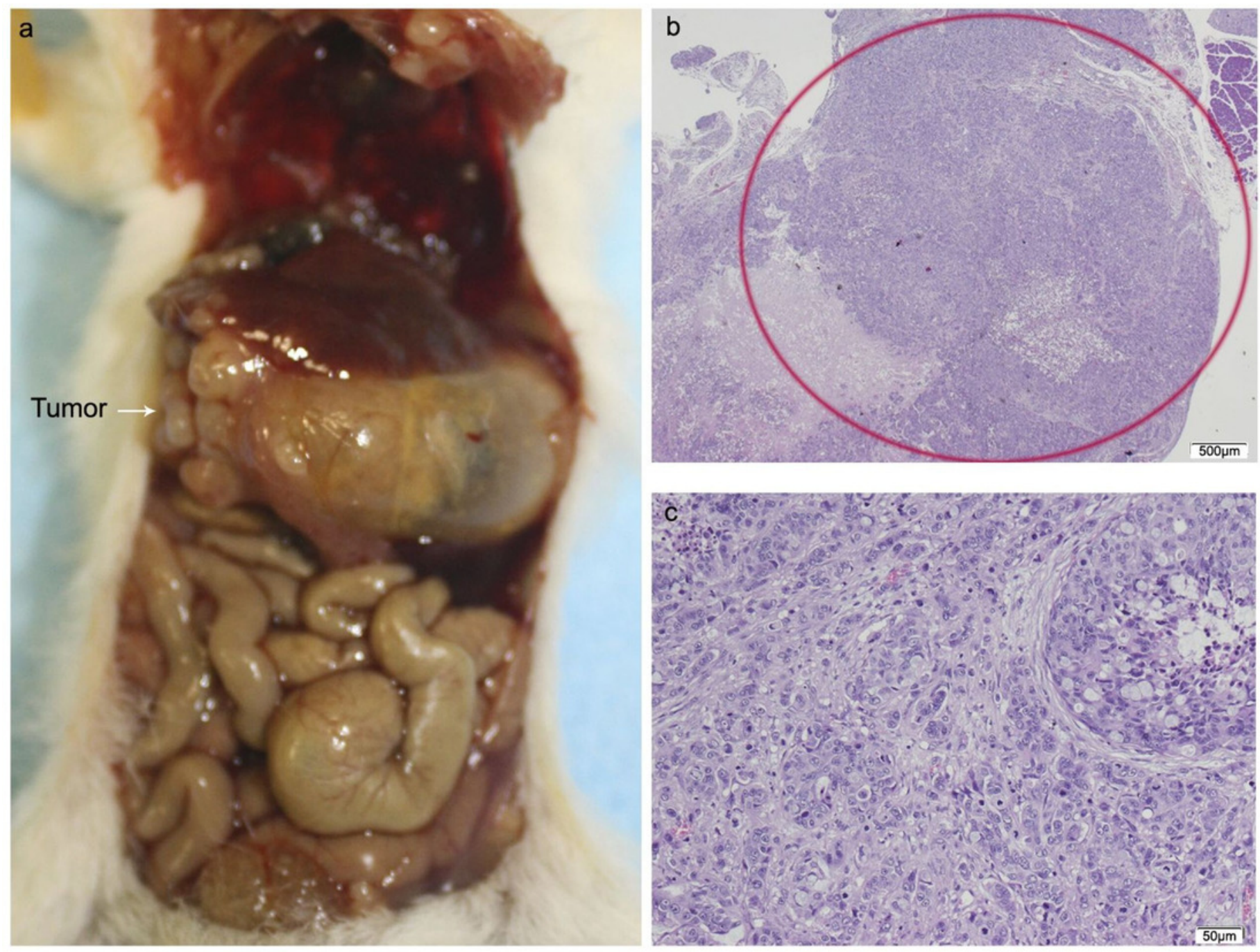
Figure 6

Relationship between pancreatic tumor and hepatic burden (A) or severity score (B)

Regression ecuations. (A) Pancreatic tumor size- hepatic burden; (B) Pancreatic tumor sizeseverity score.

A

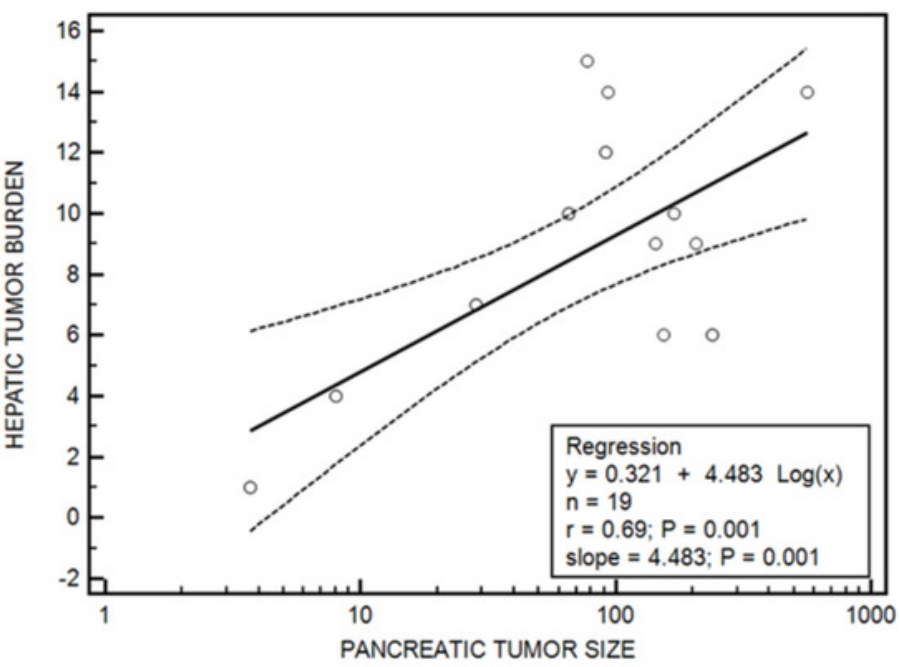

B

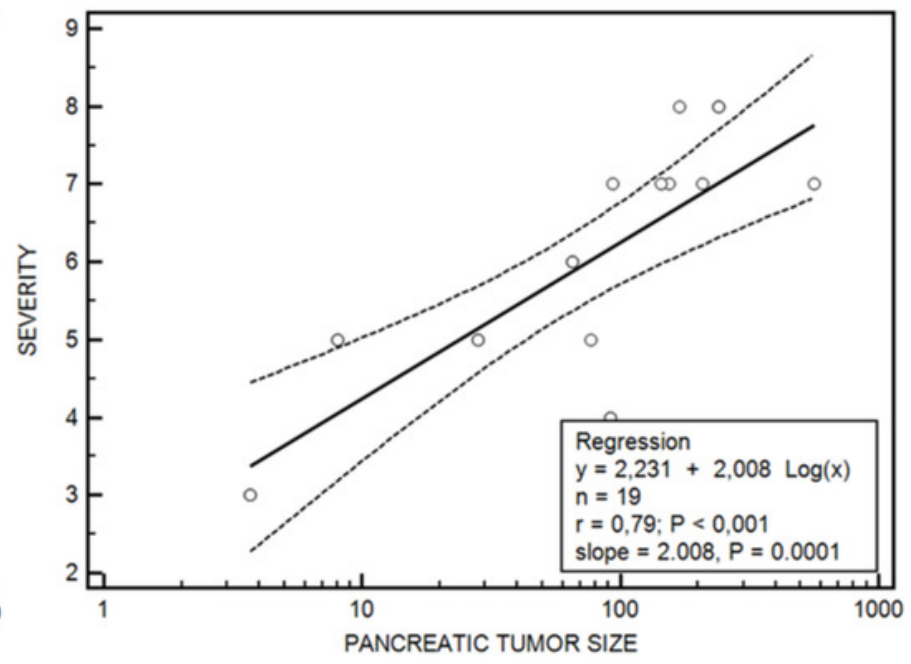

